\title{
How Decomposition and Processing Affect the Radiographic Detection of Metallic Particles from a Bullet in Gunshot Defects
}

\section{Naomi Simcha Levin ${ }^{1}$ \\ ${ }^{1}$ Texas State University \\ Abstract}

A significant portion of forensic anthropological cases involve decomposed or fragmented human skeletal remains. When testifying in a courtroom, the focus is often on trauma interpretation and distinguishing between blunt force trauma, sharp force trauma, or high-velocity projectile trauma. Therefore, forensic anthropologists need to understand how various factors and processes alter human remains during the decomposition process and how those changes affect the interpretation of skeletal trauma patterns. The primary research question addressed in this study is: how does the decomposition and processing of human remains impact the preservation of metallic fragments from gunshot trauma? Fifteen hog (Sus scrofa) crania were shot with hollow-point and full-metal jacketed $9 \mathrm{~mm}$ ammunition from an 8-foot firing distance. Eight skinless slabs of hog ribs were shot using the same ammunition types as the crania. All hog samples decomposed in an outdoor environment under metal cages to prevent scavenging. Radiographs were taken of each hog sample before and after decomposition and after processing. The results show metallic fragments from the bullet embedding in the soft tissue more frequently than in the hard tissue. Scavenging, mummification, and processing are three critical factors that were found to influence the removal/preservation of metallic fragments during the decomposition process.

Key Words: Trauma; Ballistics; Biological; Radiographs.

Introduction

Gun-related crimes in the U.S. have great impacts on individuals and communities, resulting in emotional and physical trauma (Carrega, 2019; Dent et al., 2004; National Institute of Justice, 2019; Herrmann \& Bennett, 1999; Tersigni-Tarrant \& Shirley, 2012; SangerKatz \& Bui, 2019; Towers et al., 2015). Forensic anthropologists need to understand how various factors influence methods commonly used to detect and distinguish trauma. Many forensic anthropology cases involve the interpretation of trauma from decomposed or fragmented human remains. Trauma can be classified as blunt-force trauma (BFT), sharp force trauma (SFT), projectile trauma (also known as gunshot trauma or wounds, GSW), or a combination of types. Forensic anthropologists need to understand how various factors and processes alter human remains during the decomposition process and how those changes affect skeletal trauma patterns.

In some cases, the forensic anthropologist must distinguish between BFT and GSW, which can be complicated by decomposition and taphonomic processes (Gun Violence Archive, 2020; Hollerman et al., 1990; Megyesi et al., 2005; Smith et al., 1993; Taborelli et al., 2012). Taphonomic processes include any process or event which may alter the state of remains after death such as animal scavenging, weathering, or root etching from plants. Decomposition may lead to analytical complications, particularly during the advanced stages when soft tissue deteriorates and may no longer 
hold the skeletal remains intact. Metallic particles from bullets often lodge in the soft tissue which is lost or degraded during the decomposition process. It may also become easier for skeletal segments to become separated and lost or missed during collection of remains from the scene, resulting in incomplete remains for analysis.

The presence (or absence) of radiopaque materials - in particular, metal is one method used to differentiate between BFT and GSW. Radiopaque material, metal from the bullet, will not appear in a case of BFT because a bullet is not involved. Radiopaque material appears in radiographs as material brighter than the surrounding bone and tissue with clearly defined borders. However, it is unknown how frequently radiopaque materials are discovered in GSW in skeletal remains. This study aims to estimate the reliability of using radiographs for analyzing skeletal defects from high-velocity projectile trauma in remains that have been exposed to environmental and taphonomic processes. The question being addressed in this paper is: how do decomposition and processing affect metallic fragments from GSW impact trauma in skeletal remains?

Radiopaque materials have been used in several studies to identify GSWs (Hollerman et al., 1990; Vass, 2001). Radiographs can be used to differentiate between GSW and BFT because the bullet may fragment or embed in the surrounding target (Herrmann \& Bennett, 1999). Researchers Herrmann and Bennett (1999) radiographed fleshed pig femurs and did not let them decompose. While taphonomic processes and decomposition are not typically considered in these studies, the study conducted by Willey and Scott (1996) is an exception. Their analyses were conducted after long-term burial and excavation of skeletal remains from the 1876 Battle of the Little Bighorn.

Bullets and bullet fragments may be embedded and retained in the hard and soft tissues of the bullet tract (Weiss et al., 2017). Hollow-point (HP) bullets expand upon impact with a target as a result of their open tips. This produces a mushrooming effect, creating a larger wound tract and increasing overall damage to the target. The HP bullet is designed to fragment and produce jagged edges upon impact. While HP bullets fragment and embed in the target, fullmetal-jacketed (FMJ) bullets typically react oppositely. Full-metal-jacketed ammunition is not designed to mushroom, which produces less damage to the target (Fackler, 1986). This may also result in a decreased frequency of embedding in the target and a greater rate of entrance-exit defects. Bullet fragmentation and retainment have been studied at length (Fackler, 1986; Langley et al., 2018; Weiss et al., 2017); however, the samples were not exposed to environmental and taphonomic processes when analyzed, which could significantly influence the radiographic detection of bullets and metallic fragments.

\section{Samples \\ Materials and Methods}

For this study, fifteen fleshed hog heads and eight skinless slabs of ribs were purchased from local grocery stores. The heads and ribs were all of comparable weight and size, weighing approximately ten pounds each.

\section{Environment}

The hog (Sus scrofa) samples were placed in an unshaded, grassy area at the Forensic Anthropology Research Facility (FARF) at Texas State University 
Table 1. San Marcos. TX Climate Data April-Julv 2019

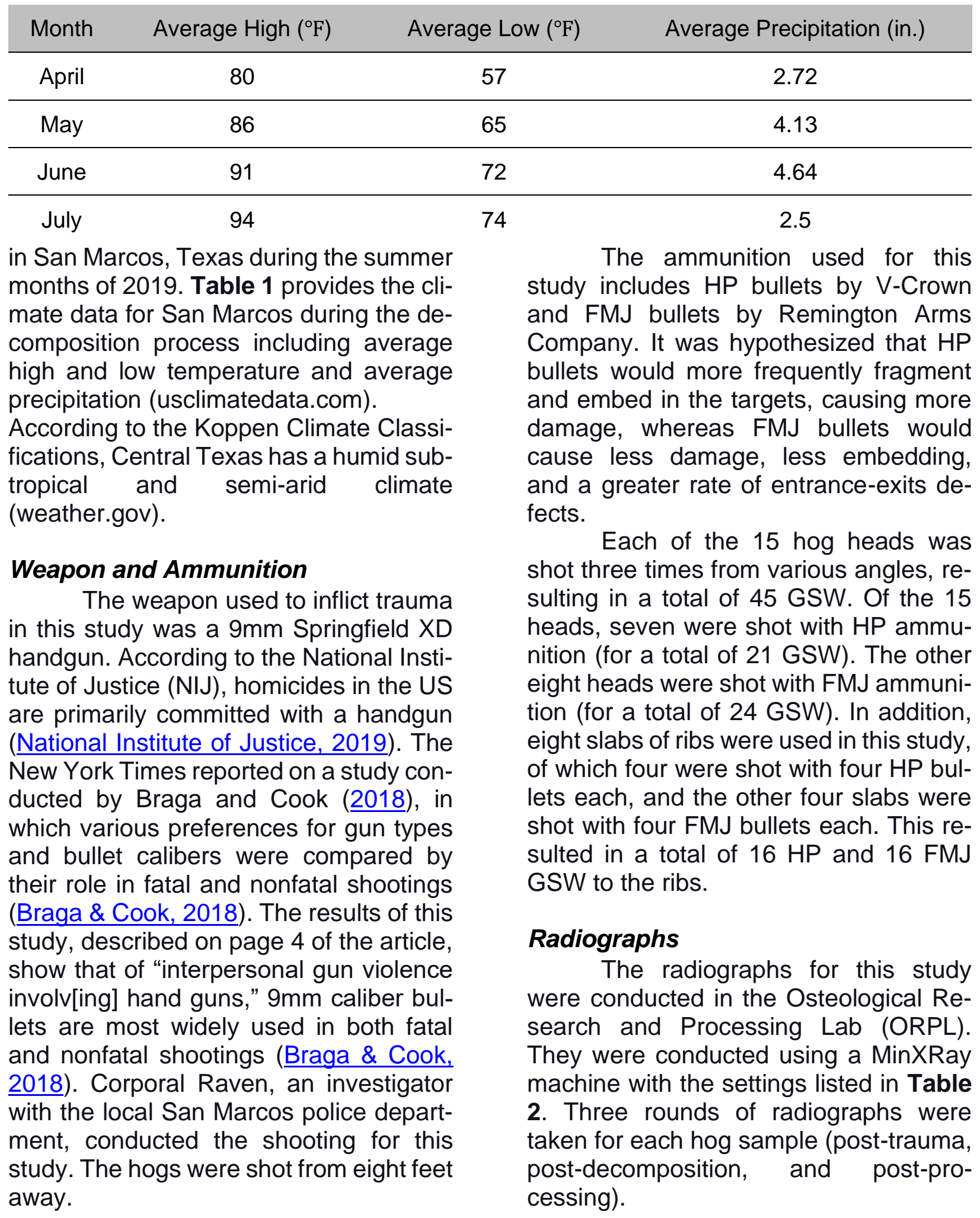


Table 2. MinXRay Settings

\begin{tabular}{ccccc} 
Element & Condition & Height of beam & $\mathrm{kV}$ & $\mathrm{mAs} / \mathrm{sec}$ \\
\hline Hog crania & Dry & $40 \mathrm{~cm}$ & 46 & 4.2 \\
\hline Hog cranial fragments & Dry & $33.5 \mathrm{~cm}$ & 40 & 3.5 \\
\hline Hog crania & Decomposed, mummified & $40 \mathrm{~cm}$ & 46 & 4.2 \\
\hline Hog ribs & Decomposed, mummified & $40 \mathrm{~cm}$ & 52 & 4.0
\end{tabular}

Maceration with Low Heat and Processing

The decomposed samples were disarticulated at the FARF and brought to the ORPL for post-decomposition and post-maceration/processing (with low heat) radiographs. Maceration is a method for cleaning bone that uses water to break down soft tissue without additional heat or chemicals. This method was modified slightly for this study to quicken the process (i.e., utilizing enzymatic maceration in which chemical enzymes are used to accelerate the breakdown of soft tissue). The pig samples soaked in a kettle for roughly nine hours with increased temperature at about $100^{\circ} \mathrm{C}$ and 1-2 oz of Alconox Terg-azyme $\AA$ powdered detergent to aid in the breakdown of the soft tissues (Dent et al., 2004). Once the soft tissues were broken down, the cartilage and soft tissues were manually removed using Dawn ${ }^{\circledR}$ dish soap, a plastic toothbrush, and metal utensils including scalpels and tweezers.

\section{Results \\ Hollow-point Radiographs}

Radiographs taken post-trauma (PT) show a $100 \%$ detection rate of metallic particles for both the HP crania and ribs. Post-decomposition (PD), four of the hog crania (57\%) shot with HP bullets showed a positive detection of metallic particles, presenting a total of six $(6 / 21=28.6 \%)$ embedded rounds which were identified in the radiographs (Figure 1). The other three crania (43\%) presented dispersed radiopaque material (ROM) fragments which could not be associated with individual defects or rounds. The PD results for the HP crania sample show a $100 \%$ radiographic detection rate as each head had varying patterns or amounts of ROM. The hog heads were radiographed for a third and final time post-processing (PP). After processing, two heads (28\%) tested positive for ROM with 15 metal fragments detected (seven in one head and eight in the other) as seen in Table 3 and Figure 2. There was a $0 \%$ change in ROM detection from PT to PD because all crania still showed some form of ROM PD.

There was a $72 \%$ drop in the percent of HP crania which retained ROM PP.

Once the ribs progressed through the decomposition process at the FARF, the slabs of ribs could not be kept together in their respective groups due to commingling in the field, and so results are presented for the rib sample as a whole, not for each slab individually. When scored as a group, 18 metallic fragments were radiographically detected PD. No clear groupings of ROM were observed. The detection rate PP was $0 \%$ as no ROM was present. 
Figure 1: The four crania PD showing a total of 6 clear, embedded HP rounds, marked with red boxes.

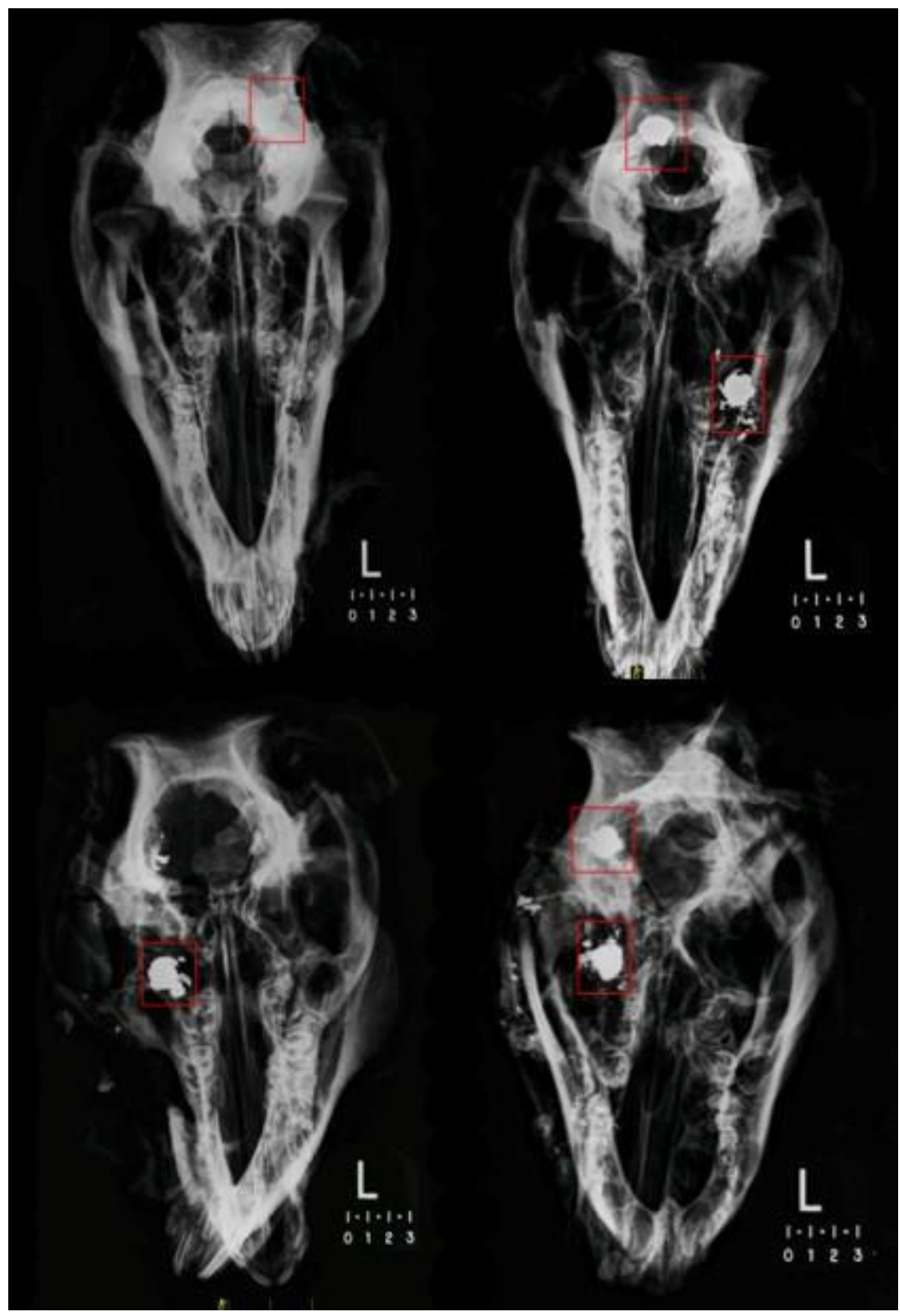

Levin, N.S. (2021) How Decomposition and Processing Affect the Radiographic Detection of Metallic Particles from a Bullet in Gunshot Defects. New Florida Journal of Anthropology 2(1):1-14. 


\section{Full-metal Jacketed Radiographs}

The rate of radiographic detection of metallic fragments in the FMJ crania samples was $100 \%$, and each of the 24 rounds could be identified PT. The rate of radiographic detection $\mathrm{PD}$ decreased to $75 \%$, with six of the eight crania showing radiopaque material. Three intact, embedded rounds were detected, in addition to 20 metallic fragments. After the crania were macerated and processed, four heads tested were positive for ROM $(4 / 8=50 \%)$ (Table 3$)$. There was an equal $25 \%$ decrease in the percent of the FMJ crania which retained ROM from PT to PD and from PD to PP. The ribs tested were positive for ROM PT, and negative for ROM PD and PP.

\section{Scavengers}

The FARF is surrounded by fencing which blocks most terrestrial scavengers from entering the facility. Prominent scavenging activity that occurs at the FARF is due to insect activity and avian scavenging. There have been several studies conducted at the FARF which study the decomposition process in this environment (Parks, 2011; Spradley et al., 2012; Suckling et al., 2016). Reeves (2009) documented the scavenging patterns of two species of vultures observed at the FARF using personal observations and digital recordings (Reeves, 2009). American black vultures (Coragyps atratus) and turkey vultures (Cathartes aura)

Figure 2: The two hog crania which tested positive for ROM during PP. These were shot with HP ammunition. 8 ROM fragments persisted after maceration in the skull in image $A$, and 7 ROM fragments persisted in the skull in image $B$.

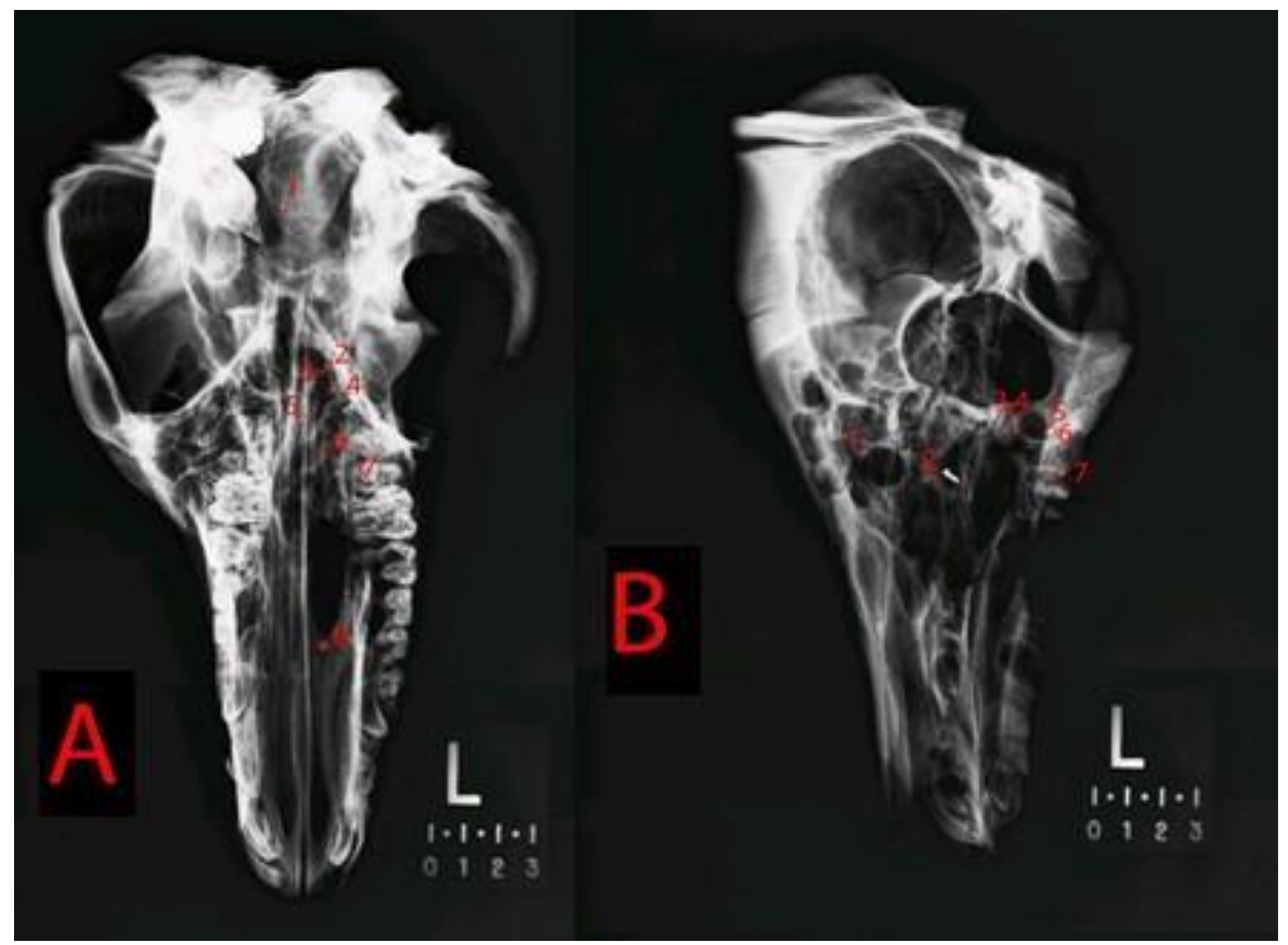

Levin, N.S. (2021) How Decomposition and Processing Affect the Radiographic Detection of Metallic Particles from a Bullet in Gunshot Defects. New Florida Journal of Anthropology 2(1):1-14. 
Table 3. Percent Positive for ROM by Phase and Ammunition Type

\begin{tabular}{ccc} 
Phase & $\begin{array}{c}\text { Ammuni- } \\
\text { tion }\end{array}$ & $\begin{array}{c}\text { Percent of crania } \\
\text { positive for ROM } \\
(\%)\end{array}$ \\
\hline PT & HP & 100 \\
\hline PD & HP & 100 \\
\hline PP & HP & 28 \\
\hline PT & FMJ & 100 \\
\hline PD & FMJ & 75 \\
\hline PP & FMJ & 50
\end{tabular}

increased the rate of decomposition and produced distinct patterns of destruction to the bone. In the current study, sets of remains were placed under metal cages at the FARF to specifically protect them from avian scavenging. The vultures have adapted to this practice by pulling at the distal limbs through spaces in the cages and protective chicken-wire which is wrapped around the sides of each cage. Higher rates of damage and modification can be seen on remains which are nearest the cage walls, as opposed to remains in the center of the cage. In this study, this behavior was observed on one HP cranium which was pulled to the edge of the cage and was left fully skele- tonized PD. The remaining hog samples were mummified and not scavenged by vultures.

It is unclear the extent to which insect activity influenced the results as this was not a focus of the study. More attention was given to the effects of avian scavenging than insect activity.

\section{Statistical Tests}

A G-test for Goodness of Fit was run using the SAS statistical program to test the significance of radiographic detection in the crania samples PT, PD and PP (Table 4). For the HP samples, decomposition and processing, statistically, showed the same weight of influence ( $p=0.086$ for both $P D$ and $P P$ ) on radiographic detection of bullet fragments. The only statistically significant change $(p=0.05)$ occurred from PT to PP for FMJ bullets. Though not statistically significant, Table 4 shows that processing the remains had a greater influence on the reliability of radiographs than did decomposition for FMJ crania ( $\mathrm{p}=0.148$ PD$>P P ; p=0.592$ PT- $>P D)$. There was a larger decrease in bullet fragments radiographically detected PP than PD.

Table 4. G-Test for Goodness of Fit 1:1 Ratio

\begin{tabular}{cccc} 
Bullet & PMI & G & P 2 tail \\
\hline HP & PT -> PD & 0 & 1 \\
\hline HP & PT -> PP & 2.942 & 0.086 \\
\hline HP & PD $>$ PP & 2.942 & 0.086 \\
\hline FMJ & PT -> PD & 2.87 & 0.592 \\
\hline FMJ & PT -> PP & 3.855 & $0.05^{\star}$ \\
\hline FMJ & PD -> PP & 2.093 & 0.148
\end{tabular}

${ }^{*}$ Denotes statistically significant result 
A Fisher's Exact test was used to determine if the bullet type influenced the detection pattern through time. The data were run using the SAS statistical program. There were no statistically significant differences between bullet type and number of crania with detectable ROM at any treatment phase (PT, PD, PP) for the crania (Table 6, $p=.0752$ ). Regardless of bullet type, the pattern of ROM evidence loss is consistent from PT to PP for the crania. A Fisher's Exact test (Table 5) was used to examine differences in the number of radiopaque fragments (ROF) and the loss of those fragments through time. As expected, the HP ammunition produced more ROM fragments which decreased in detection frequency from PT to PP but at a slightly slower rate than the FMJ ammunition. There was a signi-

Fisher's Exact Test

Table 5. Table of Fragments in Crania by Bullet Type and PMI

Table Probability $(\mathrm{P}) \quad 0.0179^{*}$

\begin{tabular}{|c|c|c|c|c|}
\hline PMI & & FMJ & HP & Total \\
\hline \multirow[t]{5}{*}{ PT } & Frequency & 36 & 102 & 138 \\
\hline & Expected & 33.379 & 104.62 & \\
\hline & Percent & 13 & 36.82 & 49.82 \\
\hline & Row Pct & 26.09 & 73.91 & \\
\hline & Col Pct & 53.73 & 48.57 & \\
\hline \multirow[t]{5}{*}{ PD } & Frequency & 26 & 93 & 119 \\
\hline & Expected & 28.783 & 90.217 & \\
\hline & Percent & 9.39 & 33.57 & 42.96 \\
\hline & Row Pct & 21.85 & 78.15 & \\
\hline & Col Pct & 38.81 & 44.29 & \\
\hline \multirow[t]{5}{*}{ PP } & Frequency & 5 & 15 & 20 \\
\hline & Expected & 4.8375 & 15.162 & \\
\hline & Percent & 1.81 & 5.42 & 7.22 \\
\hline & Row Pct & 25 & 75 & \\
\hline & Col Pct & 7.46 & 7.14 & \\
\hline
\end{tabular}


Table 6. Table of Crania with ROM based on bullet type and PMI Fisher's Exact Test

Table Probability $(\mathrm{P}) \quad 0.0752$

\begin{tabular}{ccccc} 
PMI & & FMJ & HP & Total \\
\hline PT & Frequency & 8 & 7 & 15 \\
\hline & Expected & 7.9412 & 7.0588 & \\
\hline & Percent & 23.53 & 20.59 & 44.12 \\
\hline Row Pct & 53.33 & 46.67 & \\
\hline Col Pct & 44.44 & 43.75 & 13 \\
\hline & Frequency & 6 & 7 & 38.24 \\
\hline & Expected & 6.8824 & 6.1176 & \\
\hline & Percent & 17.65 & 20.59 & \\
\hline PP & Row Pct & 46.15 & 53.85 & 17.65 \\
\hline Col Pct & 33.33 & 43.75 & \\
\hline & Frequency & 4 & 2 & \\
\hline & Expected & 3.1765 & 2.8235 & \\
\hline & Percent & 11.76 & 5.88 & \\
\hline & Row Pct & 66.67 & 33.33 & 12.5 \\
\hline Col Pct & 22.22 & & \\
\hline
\end{tabular}

ficant difference in the amount of ROF lost throughout the experiment $(\mathrm{p}=.0179)$ (Table 5). Finally, the ribs presented a different pattern (Table 7). There is a significant difference $(p=.0005)$ in ROM detection between the rib samples PT and PD. No ROM was detected in the FMJ rib sample PD. For the HP there were still detectable ROMs until after maceration. This difference is also probably due to the reduced fragmentation of the bullet in FMJ ammunition.

\section{Discussion}

Interpretations of trauma patterns can impact an investigation by providing useful information about the cause and manner of death. The accuracy of anthropological trauma interpretations can decrease due to several factors that were tested in this study, as discussed below. This study focused on the persistence of metallic bullet fragments through various taphonomic processes using the widely used method of radiographic detection. The validity of this method was tested on decomposed and environmentally ex- 
Table 7. Table of Ribs with ROM based on Bullet Type and PMI

Fisher's Exact Test

Table Probability $(\mathrm{P}) \quad 0.0005^{\star}$

\begin{tabular}{|c|c|c|c|c|}
\hline PMI & & FMJ & HP & Total \\
\hline \multirow[t]{5}{*}{ PT } & Frequency & 25 & 39 & 64 \\
\hline & Expected & 19.512 & 44.488 & \\
\hline & Percent & 30.49 & 47.56 & 78.05 \\
\hline & Row Pct & 39.06 & 60.94 & \\
\hline & Col Pct & 100 & 68.42 & \\
\hline \multirow[t]{5}{*}{ PD/PP } & Frequency & 0 & 18 & 18 \\
\hline & Expected & 5.4878 & 12.512 & \\
\hline & Percent & 0 & 21.95 & 21.95 \\
\hline & Row Pct & 0 & 100 & \\
\hline & Col Pct & 0 & 31.58 & \\
\hline
\end{tabular}

posed samples of gunshot trauma.

According to Di Maio (1999), lead shavings from the bullet may embed themselves in the gunshot wound if the bullet and barrel are not in perfect alignment, as may be the case in a poorly made revolver or handgun ( $\mathrm{Di}$ Maio, 1999). The fragments come not from the bullet's misalignment with the barrel but from its impact with the target and the design of the bullet's jacketing. The results of this study confirm Di Maio's statements that fragments embed in the skin, and enhance our understanding of where fragments can be embedded and detected in GSWs. In this study, ROM was also found embedded in the deeper soft tissue and bone structures. Poor craftsmanship of a gun may have some impact on how the bullet responds and reacts to target impact, but this study shows that where the bullet penetrates in the body, the type of ammunition used and the condition of the remains during analysis also play important roles in the detection of ROM in gunshot defects.

\section{Effect of Scavenging}

Radiographs of remains which show evidence of scavenging should be interpreted with caution. The aridity of this area in Central Texas during the summer months can lead to mummification of the soft tissue. Since metallic fragments most often embed in the soft tissue, the mummification process preserved the embedded metallic fragments which are used for trauma interpretation of GSWs. Summer rain can, in turn, rehydrate those soft tissues which can result 
in accelerated decomposition (Galloway et al., 1989). Avian scavenging can significantly increase the rate of decomposition, leaving a previously fresh set of remains completely skeletonized in five hours (Spradley et al., 2012). This can severely decrease the reliability of radiographic detection by increasing the degradation of important forensic evidence.

\section{Effect of Decomposition and Pro- cessing}

The reliability of radiographically detecting metallic fragments in the interpretation of GSW highly depends on the preservation of hard and soft tissues. The results presented in this paper show that mummification of soft tissue and removal of soft tissue by avian scavengers and processing directly impacts the reliability of this method of detection. Decomposition had no statistically significant effect on radiographic detection. This is likely due to the mummification of the soft tissue which preserved the metallic fragments. In contrast, the hog cranium which was scavenged had no soft tissue remaining. This hog cranium tested negative for metallic fragments after the decomposition process. The largest decrease in radiographic detection of ROM occurred PP. This supports the statement by Rogers (1992) that radiographs should be taken before any maceration or processing of remains suspected of having GSW (Rogers, 1992). It is suggested to always have a screen in the sink drain which may catch any loose metallic particles during processing. Prior to dumping and incineration, radiographs of soft-tissue bags should be taken as there could be potential ROM.

\section{Effect of Ammunition Type}

The HP and FMJ gunshot defects presented different patterns of ROM in the target. The GSW resulting from FMJ bullets were identified primarily by the grouping of ROMs, whereas HP GSWs showed more dispersed ROM. Due to the structure of HP bullets and their subsequent deformation (i.e., expanding to form a "mushroom," fragmentation; $\underline{\mathrm{Hol}-}$ lermann et al., 1990), significantly greater amounts of ROM fragments were seen in the radiographs compared to the FMJ samples. "Mushrooming" is an important variable which leads to increased ROFs, because when the "petals" expand outward they can separate from the main bullet and lodge into the surrounding tissue and bone. Bullet design is a vital factor which can lead to differences in ROM detection as observed in this study. While the pattern of radiographic detection of ROM between the two ammunition types was not significantly different, the morphology and structure of the ROM were distinguishable (Figure 3).

\section{Conclusion}

This study highlights that radiography for trauma interpretation should be conducted prior to the removal of any soft tissue elements. By modifying and removing soft tissue, the radiographic detection rate of ROM decreases. When examining skeletal remains, the positive detection of ROM is evidence of gunshot trauma but the absence of ROM does not necessarily mean there is no gunshot trauma present. Previous research indicates that lead shavings from a bullet embed in the skin if the bullet and barrel are not in perfect alignment (Di Maio, 1999). Building on Di Maio's (1999) statement, this research also indicates the retention of bullet fragments at a greater depth (i.e., in skeletal tissue), and that fragments can also originate from the bullet's impact with the target, with further variation based on the design of its jacketing. 
Figure 3: Image A (top) is an example of a $P D$ radiograph (post-decomposition) of a hog cranium shot with hollow point ammunition. Image $B$ (bottom) is an example of a $P D$ radiograph of a hog cranium shot with full metal jacketed ammunition. Note the difference in

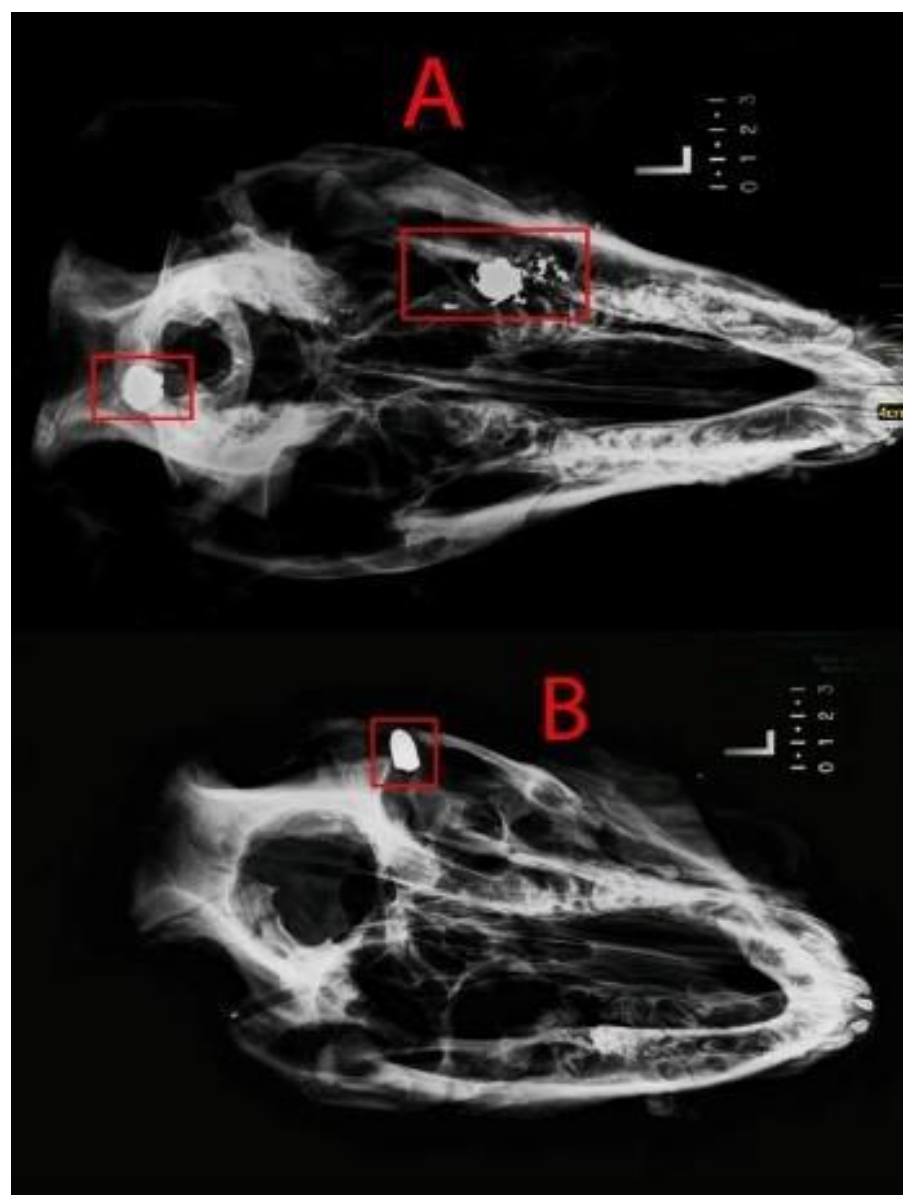

Based on the results of this study, it can be suggested that those in the field of Forensic Science, including anthropologists and medical examiners, should take a portable metal detector to the crime scene. This can be used to detect metallic fragments from bullets if remains have been decomposed, scavenged, or skeletonized. It is recognized that some metal detectors may be costly and logistically difficult to bring to scenes, however, there are smaller metal detectors which can be easily maneuvered in a variety of scenarios and can be purchased with a limited budget. It is also suggested that radiographs be conducted prior to any autopsy or processing of remains. Any soft tissues that are removed should also be radiographed prior to disposal. Radiographs should be used in conjunction with other analytical methods for trauma interpretations. The reliability of this method of metallic fragment detection is highly variable and dependent on the environment in which the remains are deposited in and the condition in which those remains are found. Metal detectors would be useful at the scene for detecting bullet fragments in the spot where the body was deposited, i.e., directly underneath the remains. Further studies could include larger hog sample sizes or use donated human remains. Additional studies may test a greater variety of ammunition types and weapons since bullet design was determined to be an integral variable in the differences observed in ROM detection in this study. Other studies could place the samples outside a cage to directly test the effects of scavenging or insect activity on the reliability of radiographic detection of metallic fragments. Additional studies should also be conducted in various different climates and seasons.

\section{References}

Austin Climate Summary. https://www.weather.gov/media/ewx/climate/ClimateSummary-ewx-Austin.pdf

Braga, A. A., \& Cook, P. J. (2018) The Association of Firearm Caliber With Likelihood of Death From Gunshot Injury in Criminal Assaults. JAMA Network Open, 1(3), e180833-e180833.DOl: 10.1001/iamanetworkopen.2018.0833

Carrega, C. School shootings are more common than you think: A look at the incidents that went under the radar in 2019. ABC News 2019. 
Dent, B. B., Forbes, S. L., \& Stuart, B. H. (2004) Review of human decomposition processes in soil. Environmental Geology 45(4):576-85. DOI: 10.1007/s00254-003-0913-z

Di Maio, V. (1999) Gunshot Wounds: Practical Aspects of Firearms, Ballistics, and Forensic Techniques ( $2^{\text {nd }}$ ed.). Boca Raton, New York: CRC Press.

Fackler, M. L. (1986) Ballistic injury. Annals of Emergency Medicine, 15(12): 14521455. DOI: 10.1016/S0196$\underline{0644(86) 80941-6}$

Galloway, A., Birkby, W. H., Jones, A. M., Henry, T. E., \& Parks, B. O. (1989) Decay Rates of Human Remains in an Arid Environment. J Forensic Sci, 34(3):12680J. DOI: 10.1520/JFS12680 J

Gun Violence Archive. 2020. www.gunviolencearchive.org

Gun Violence in America. 2019. National Institute of Justice. nij.ojp.gov: https://nii.ojp.gov/topics/articles/gun-violence-america

Herrmann, N.P. \& Bennett, J. L. (1999) The differentiation of traumatic and heat-related fractures in burned bone. $J$ Forensic Sci, 44(3):461-9. DOI: 10.1520/JFS14495J

Hollerman, J. J., Fackler, M. L., Coldwell, D. M., \& Ben-Menachem, Y. (1990) Gunshot wounds: 1. Bullets, ballistics, and mechanisms of injury. American Journal of Roentgenology. 155(4):68590. DOI: 10.2214/ajr.155.4.2119095

Langley, N., West, J., Kunigelis, S., \& Boggs, C. (2018) Making up for Missing Pieces: SEM-EDS Gunshot Residue Analysis of Human Cranial Bone. FA, 1(1):74-9. DOI: 10.5744/fa.2018.0007
Megyesi, M. S., Nawrocki, S. P., \& Haskell, N. H. (2005) Using Accumulated Degree-Days to Estimate the Postmortem Interval from Decomposed Human Remains. J Forensic Sci, 50(3):1-9. DOI: 10.1520/JFS2004017

Parks, C. L. (2011) A Study of the Human Decomposition Sequence in Central Texas. J Forensic Sci, 56(1):19-22. DOI: 10.1111/j.1556$\underline{4029.2010 .01544 . x}$

Reeves, N. M. (2009) Taphonomic Effects of Vulture Scavenging. J Forensic Sci, 54(3):523-8. DOI: 10.1111/j.15564029.2009.01020.x

Rogers, L. F., (1992) Radiology of Skeletal Trauma. $2^{\text {nd }}$ ed. New York: Churchill Livingstone.

Sanger-Katz, M. \& Bui, Q. People kill people. But the bullets seem to matter. The New York Times 2019.

Smith, O. C., Berryman, H. E., Symes, S. A., Francisco, J.T., \& Hnilica, V. (1993) Atypical gunshot exit defects to the cranial vault. J Forensic Sci, 38(2), 339343. DOI: 10.1520/JFS13413J

Spradley, M. K., Hamilton, M. D., \& Giordano, A. (2012) Spatial patterning of vulture scavenged human remains. Forensic Science International, 219(13):57-63. DOI: 10.1016/i.forsciint.2011.11.030

Suckling, J. K., Spradley, M. K., \& Godde, K. (2016) A Longitudinal Study on Human Outdoor Decomposition in Central Texas. J Forensic Sci, 61(1):19-25. DOI: /10.1111/1556-4029.12892

Taborelli, A., Gibelli, D., Rizzi, A., Andreola, S., Brandone, A., \& Cattaneo, C. (2012) Gunshot Residues on Dry Bone After Decomposition-A Pilot Study. J Forensic Sci, 57(5):1281-4. DOI: 10.1111/j.1556-4029.2012.02119.x

Levin, N.S. (2021) How Decomposition and Processing Affect the Radiographic Detection of Metallic Particles from a Bullet in Gunshot Defects. New Florida Journal of Anthropology 2(1):1-14. 
Tersigni-Tarrant, M. A. \& Shirley, N. R., editors. Forensic Anthropology: An Introduction. CRC Press, 2012.

Towers, S., Gomez-Lievano, A., Khan, M., Mubayi, A., \& Castillo-Chavez, C. (2015) Contagion in Mass Killings and School Shootings. PLOS ONE, 10(7):e0117259. DOI: 10.1371/journal.pone.0117259

US Climate Data. San Marcos, Texas. San Marcos, Texas. usclimatedata.com

Vass, A. A. (2001) Beyond the grave- understanding human decomposition. Microbiology Today, 28:190-2.

Weiss, D., Lee, D., Feldman, R., \& Smith, K. E. (2017) Severe lead toxicity attributed to bullet fragments retained in soft tissue. BMJ Case Reports, bcr2016217351. DOI: $10.1136 / \mathrm{bcr}-$ 2016-217351

Willey, P. \& Scott, D. D. (1996) "The Bullets Buzzed Like Bees": Gunshot wounds in skeletons from the Battle of the Little Bighorn. International Journal of Osteoarchaeology, 6, 15-27. DOI: 10.1002/(SICl)10991212(199601)6:1<15::AIDOA258>3.0.CO;2-J 